\title{
Noticia de Revistas Autonómicas ${ }^{1 *}$ \\ (1) § Unión Europea, Comunidades Autónomas, Derecho autonó- mico,Distribución de competencias.
}

Arrese Iriondo, $\mathrm{M}^{\mathrm{a}}$ Nieves: «Competencia de las comunidades autónomas en materia de sanidad y asistencia sanitaria a las personas migrantes en situación irregular», Revista Aragonesa de Administración Pública, núm. 47-48, 2016, pp. 210-243.

Como se conocido, el Real Decreto-Ley 16/2012, de 20 de abril, de medidas urgentes para garantizar la sostenibilidad del Sistema Nacional de Salud y mejorar la calidad y seguridad de sus prestaciones, adoptado en la fase más crítica de la crisis económica, reservó la atención sanitaria con cargo a fondos públicos, a través del Sistema Nacional de Salud, exclusivamente a las personas que tengan la condición de asegurado o beneficiario, lo que supuso la exclusión, con carácter general, de las personas extranjeras en situación irregular (salvo las modalidades de urgencia por enfermedad grave o accidente, hasta la situación de alta médica y de asistencia al embarazo, parto y postparto, así como la atención a menores).

Sin embargo, algunas Comunidades Autónomas reaccionaron extendiendo su sistema sanitario también a estas personas, aunque con distinta amplitud. Este trabajo analiza tanto la diversa respuesta de las Comunidades Autónomas (en particular, a partir de las elecciones autonómicas de 2015), como los términos constitucionales de este conflicto competencial, a partir de los títulos competenciales en juego y acerca de la licitud de las normas autonómicas adoptadas en ejercicio de sus competencias en materia sanitaria.

(2) § Administraciones Públicas/Función Pública.

(3) § Derechos Fundamentales, Potestad Reglamentaria, Acto, Procedimiento administrativo y Contratación. Control Jurisdiccional de las Administraciones Públicas.

Cabrera Rodríguez, José: «El ejercicio de derechos fundamentales a través de las organizaciones y los procedimientos administrativos», Revista Vasca de Administración Pública, núm. 107-I. Enero-Abril 2017. Págs. 43-85.

A partir de una dimensión jurídico-objetiva de los derechos fundamentales, el autor plantea la necesidad de tomar en consideración, en las actuales tendencias

1 " Sección a cargo de SEVERIANO FERNÁNDEZ RAMOS, Catedrático de Derecho Administrativo, Universidad de Cádiz. 
legislativas de racionalización de las organizaciones públicas y simplificación de los procedimientos administrativos, el hecho de que estas instituciones se encuentran no sólo orientadas al cumplimiento de los fines y funciones constitucionalmente asignados a los poderes públicos, sino también funcionalmente orientadas al servicio de la posibilitación y realización efectiva de derechos fundamentales. En el fondo, se trata de una perspectiva tradicionalmente presente en nuestro ordenamiento. Así, nos permitimos recordar la innegable vinculación entre el derecho al acceso en condiciones de igualdad a la función pública y la conformación de los tribunales juzgadores de los procesos selectivos, mediante criterios de imparcialidad, independencia y competencia profesional.

Más en concreto, el autor se centra en la posibilidad de una deducción interpretativa de ciertos principios organizativo-procedimentales a partir de derechos fundamentales típicamente negativos o de libertad cuya virtualidad tuitiva se extendería así más allá de la clásica garantía subjetiva de un espacio de auto-determinación del individuo en un determinado ámbito para alcanzar, desde esta perspectiva proyección objetiva, a las estructuras organizativo-procedimentales que posibilitan o condicionan su ejercicio.

Para nuestro autor, las limitaciones constitucionales que se imponen a esta proyección organizativo-procedimental de los derechos fundamentales (lo que denomina configuración iusfundamentalmente adecuada de los derechos fundamentales) provienen fundamentalmente de la distinción entre constitucionalidad y legalidad ordinaria presente en la estructura del sistema de fuentes. En cambio, considera que el principio de eficiencia administrativa, entendido como un criterio relacional tendente a la maximización del empleo de los medios disponibles para la consecución de los fines constitucionalmente asignados a los poderes públicos, «no parece poder contraponerse legítimamente a la efectividad organizativo-procedimental de tales derechos».

Gasado Gasado, Lucía: «La incidencia de la Ley del Procedimiento Administrativo Común de las Administraciones Públicas sobre la potestad normativa local», Revista Vasca de Administración Pública, núm. 107-I. Enero-Abril 2017. Págs. 87-141.

La prfa. L. Casado Casado analiza, con su acostumbrado rigor, el impacto de las normas básicas contenidas en el Título VI de la Ley del Procedimiento Administrativo Común de las Administraciones Públicas sobre la potestad reglamentaria de las entidades locales, poniendo de manifiesto los retos que supone la nueva Ley para los gobiernos locales, así como los problemas e incertidumbres que su aplicación puede suscitar, en particular para integrar las disposiciones de la Ley 39/2015 con la Ley Básica de Régimen Local, como ley especial. Así, en relación con el procedimiento de elaboración de disposiciones reglamentarias, la autora trata la novedosa de inclusión del trámite de consulta pública previa a la redacción del anteproyecto de 
reglamento. En cambio, considera que las reglas referentes a los trámites de audiencia e información públicas de la Ley 39/2015 son compatibles con la regulación de los mismos en la Ley Básica de Régimen Local.

Igualmente, la autora trata las nuevas obligaciones relativas a la planificación y evaluación normativas. Así, en relación a la planificación normativa, pone de manifiesto la parquedad de regulación básica de esta figura lo que limitará sin duda su alcance y efectividad. Por ello, nuestra autora sugiere la regulación del Plan normativo mediante una ordenanza que determine los aspectos necesitados de concreción, y, entre los cuales, se encuentra nada menos que la determinación del órgano competente para la aprobación del Plan normativo (la autora defiende la competencia del pleno, si bien ello es discutible, en nuestra opinión). Por último, en cuanto a la evaluación normativa ex post, también la Ley 39/2015 confiere un amplio margen de maniobra, que permite a las entidades locales diversas opciones, sin que deban seguir el modelo de la Administración del Estado, plasmado en la reforma de la Ley del Gobierno. En todo caso, la profa. CASADO CASADO señala, con razón, que la labor que tienen por delante las entidades locales es inmensa.

De la Fuente Miguélez, Alberto: Aplicabilidad de la normativa sobre protección de datos de carácter personal en el ámbito de la función estadística pública», Revista Vasca de Administración Pública, núm. 107-I. Enero-Abril 2017. Págs. 275-301.

Partiendo del artículo 2.3 de la Ley Orgánica 15/1999, de 13 de diciembre, de Protección de Datos de Carácter Personal, según el cual: «Se regirán por sus disposiciones específicas, y por lo especialmente previsto, en su caso, por esta Ley Orgánica los siguientes tratamientos de datos personales: b) Los que sirvan a fines exclusivamente estadísticos, y estén amparados por la legislación estatal o autonómica sobre la función estadística pública», este trabajo indaga en qué medida puede o debe aplicarse la Ley Orgánica 15/1999 a la función estadística pública. A este respecto, el autor admite que el ejercicio de la función estadística pública conlleva una serie de particularidades que reclaman su atención específica por el texto legal dedicado a establecer el régimen que corresponde a dicha actividad pública (en el Estado, la Ley 12/1989, de 9 de mayo, de la función estadística pública), y no por el cuerpo normativo directa y principalmente destinado a configurar el desarrollo o el ejercicio de un determinado derecho fundamental (la Ley Orgánica 15/1999). Ahora bien, como bien señala el autor, el régimen de la actividad estadística pública, con todas sus especificidades y particularidades, siempre deberá ser respetuoso con el contenido esencial del derecho fundamental en juego.

A este respecto, y tras un examen del valor jurídico de las Recomendaciones del Director de la AEPD, el autor considera que la postura de esta institución, según la cual a los tratamientos de datos de carácter personal que se realicen para finali- 
dades exclusivamente estadísticas en el ámbito de la función estadística pública debe aplicarse la Ley 12/1989, pero también la Ley Orgánica 15/1999, salvo en aquellas cuestiones en las que esta última expresamente disponga su no aplicación, no se compagina con el tenor literal antes indicado de la Ley Orgánica 15/1999. No obstante, el autor se plantea la aplicabilidad de la LOPD a la función estadística pública a la luz de la doctrina del Tribunal Constitucional sobre los límites de los derechos fundamentales, lo cual lleva al autor a enjuiciar a validez constitucional de la práctica de remitir al ámbito reglamentario (Real Decreto de aprobación del Plan Estadístico Nacional) la determinación de las estadísticas que exigen el suministro obligatorio de información.

Morcillo Moreno, Juana: «Las cláusulas sociales en la contratación pública como garantía frente al dumping social intracomunitario», Revista Aragonesa de Administración Pública, núm. 47-48, 2016, pp. 180-209.

La contratación pública, habida cuenta el ingente volumen de recursos públicos que moviliza, constituye un potente instrumento transversal al servicio de las políticas de la Unión, como las políticas ambientales y, en lo que interesa en este trabajo, sociales. Así, la previsión de cláusulas sociales en los contratos públicos sirve para mediar entre la libre prestación de servicios y la protección de los trabajadores, frente al dumping social en el seno de la Unión Europea. Pues bien, en este interesante trabajo la autora comenta la STJUE de 17 de noviembre de 2015, relativa al caso «Regiopost», en la cual el Tribunal considera compatible con el Derecho de la Unión una normativa regional que, de una parte, obligaba a los licitadores y subcontratistas de un contrato público a asumir por escrito en la oferta el compromiso de pagar a sus trabajadores desplazados a otro Estado miembro el salario mínimo fijado por éste y, de otra, permitía la exclusión del procedimiento de adjudicación de aquellos licitadores que se negasen a asumir dicha obligación, como consecuencia del incumplimiento de una «norma imperativa de protección mínima», expresamente autorizada por el artículo 26 de la Directiva 2004/18.

Tras exponer la respuesta del Tribunal de Justicia a las cuestiones prejudiciales formuladas, la autora subraya la conexión que el caso «RegioPost» plantea entre las fases de adjudicación y ejecución de los contratos, pues la normativa controvertida conectaba las fases de adjudicación y ejecución de los contratos públicos, desde el momento en que la negativa en la fase de adjudicación a asumir por escrito un compromiso de cumplimiento de ciertas condiciones en la fase de ejecución del contrato público implicaría per se la exclusión misma del proceso de adjudicación. Con todo, la autora considera que los argumentos en los que el Tribunal de Justicia apoya su decisión son fundamentalmente formales («norma imperativa de protección mínima»), habiendo desaprovechado la ocasión para apostar, también de modo sustantivo, por la protección de los trabajadores de cara a aumentar la garantía frente al dumping 
social dentro de la Unión, a partir de la consideración de la protección del trabajador como «razón imperiosa de interés general.

Gómez Manresa, María Fuensanta: «Retos de la contratación pública electrónica», Revista Aragonesa de Administración Pública, núm. 47-48, 2016, pp. 244-275.

Este trabajo tiene como objeto el estudio de los retos de la utilización de los medios electrónicos, telemáticos e informáticos en el ámbito de la contratación pública, dada la oportunidad que representa para el impulso de la efectiva implementación de las TICs la futura transposición de las directivas europeas sobre contratación pública, temática ligada tanto al impulso de la competitividad, como a la transparencia y la lucha contra la lacra de la corrupción. Para ello, la autora se centra en el contexto propiciado por la nueva legislación de procedimiento administrativo común y del sector público. Así, se analizan, entre otras cuestiones, la apuesta por la simplificación en el régimen jurídico de la identificación y firma electrónicas, la nueva regulación de la representación jurídica (el apoderamiento «apud acta» electrónico), la prevalencia del dato sobre el documento y, sobre todo, la interoperabilidad como clave de la innovación tecnológica.

Pérez Estrada, Miren Josune: «La exclusiva función del actual recurso de casación contencioso-administrativo ante el Tribunal Supremo», Revista Vasca de Administración Pública, núm. 107-I. Enero-Abril 2017. Págs. 303-328.

Como es sabido, la Ley Orgánica 7/2015, de 21 de junio, reformó en profundidad el régimen del recurso de casación en el orden jurisdiccional contencioso-administrativo: básicamente, redujo las variedades anteriores de la casación a una sola (suprimiendo la casación en interés de ley y para unificación de doctrina), y cambió sustancialmente los supuestos en que cabe interponer el recurso, de tal modo que una sentencia sólo podrá ser recurrida en casación cuando el asunto debatido alcance un interés casacional objetivo - art. 88 LJCA-. Pues bien, en este trabajo se aborda la finalidad e interpretación del nuevo concepto indeterminado de «interés casacional», como instrumento para asegurar la uniformidad en la aplicación judicial del derecho mediante la formación de jurisprudencia, y su apreciación discrecional por la Sala de lo contencioso-administrativo del Tribunal Supremo.

Pero, además, el autor plantea los riesgos que entraña la instauración de un recurso que tiene por exclusivo objeto velar por la uniformidad en la aplicación del derecho (la llamada función nomofiláctica), en detrimento de la de la resolución de la cuestión que enfrenta a las partes en un proceso. En tal sentido, y tomando como referente la doctrina del Tribunal Europeo de Derechos Humanos sobre el acceso al recurso en relación con la tutela judicial efectiva, el autor cuestiona el nuevo sistema y reflexiona sobre los daños colaterales en los principios de igualdad en la aplicación del derecho, seguridad jurídica e independencia judicial. 
Trayter Jiménez, Joan Manuel: «Simplificación administrativa y modificación o supresión de las técnicas de limitación o intervención», Revista Aragonesa de Administración Pública, núm. 47-48, 2016, pp. 8-44.

Como es conocido, desde la transposición de la Directiva Servicios, con carácter general, a través de la Ley 17/2009, de 23 de noviembre, sobre el libre acceso a las actividades de servicios y su ejercicio, y de la Ley 25/2009, de 22 de diciembre, estamos asistiendo a un continuo repliegue de las autorizaciones o licencias, es decir, de las técnicas de intervención administrativa ex ante al acceso o ejercicio a la libre prestación de servicios por parte de los particulares, y a la sustitución de las mismas por la comunicación o declaración responsable de los particulares, es decir, un control que normalmente es posterior a la implantación o el ejercicio de la actividad. El prof. TrAYTER Jiménez, a partir las recientes normas de simplificación administrativa en las que se regulan las figuras de la comunicación y la declaración responsable, formula un marco general de las mismas, de los principios sobre los que se sustentan esas técnicas de limitación como mandato al legislador y como límites y criterios de interpretación al aplicador de la norma (principio general de libertad, reserva de Ley, principios de necesidad y proporcionalidad, y único medio de intervención, entre otros).

Pero, además, el trabajo analiza un conjunto de ejemplos de mala praxis plasmados en normas reglamentarias, en parte rémoras del pasado, tales como la exigencia en la presentación de la declaración responsable y la comunicación previa de un gran número de documentos, estableciendo controles o requisitos previos a su formalización que desnaturalizan esas figuras; o el carácter diferido de los efectos de la presentación de la declaración responsable y la comunicación; o la previsión de suspensión o cese de la actividad por falta de documentación. Finalmente, aun cuando la intención del legislador en este ámbito es evitar a priori la puesta en marcha de la responsabilidad administrativa, el trabajo analiza la aplicabilidad en este ámbito del instituto de la responsabilidad de la administración por daños, en aquellos casos en los que la Administración bien no ejerza sus potestades de inspección y control o bien las ejerza inadecuadamente, y como consecuencia de ello, un tercero (o los intereses públicos en según qué ámbitos) se ve afectado.

\section{(4) § Hacienda pública, Bienes, expropiación y responsabilidad.}

(5) § Modalidades administrativas de Intervención (Policía, Fomento, Servicio público, Actividad Sancionadora, Arbitral y Planificadora).

García Ureta, Agustín: «Consideraciones sobre la incidencia de las Leyes 39 y 40/2015 en la Ley 2/1998, de la potestad sancionadora de las administraciones 
públicas de la Comunidad Autónoma del País Vasco», R.V.A.P. núm. 107-I. EneroAbril 2017. Págs. 143-169.

Son ya conocidas las múltiples cuestiones que suscita la ordenación dual de la potestad sancionadora en las Leyes 39/2015 y 40/2015, en particular, la cuestionable división entre aspectos de régimen jurídico y procedimiento que dificultan una comprensión unitaria de esta potestad. En este trabajo, el autor se centra en la necesidad de cohonestar ambas leyes con la Ley 2/1998, de 20 de febrero, de la potestad sancionadora de las Administraciones Públicas de la Comunidad Autónoma del País Vasco, norma verdaderamente singular en el panorama autonómico.

Por lo que respecta al ámbito subjetivo, el autor considera que el criterio de la Ley 40/2015 de incluir al personal al servicio de las Administraciones, entra en contradicción con la perspectiva de la Ley 40/2015 orientada a los ciudadanos en general. Por su parte, en relación con los principios de la potestad sancionadora, el autor considera que las nuevas leyes estatales siguen sin recoger adecuadamente el principio general de presunción de inocencia. Ciertamente, dicho principio se recoge en la Ley 3972015 entre los derechos del interesado «en el procedimiento administrativo», pero el prof. García Ureta defiende que debería haberse incluido expresamente entre los generales de la potestad sancionadora en la Ley 40/2015. Igualmente, nuestro autor echa en falta una regulación más completa de los tipos de infracciones, a pesar de la inclusión de referencias sobre las continuas y permanentes, y los concursos (a diferencia de las previsiones de la LPS). Otro tanto cabría señalar en relación con el principio non bis in idem. Desde la perspectiva procedimental, la introducción del denominado procedimiento «simplificado», la regulación del denunciante colaborador con la Administración y la inclusión expresa del reconocimiento de la responsabilidad, son señaladas también como novedades destacables que inciden en la Ley 2/1998, de 20 de febrero, al no prever ésta tales situaciones.

Izquierdo Carrasco, Manuel - Alcántara Reifs, Juan Jesús: «Límites materiales y territoriales a la actuación de la policía local como policía judicial: a propósito de la STS n. ${ }^{\circ}$ 210/2016, Sala 2. a, de lo Penal, de 15 de marzo de 2016», R.V.A.P. núm. 107-I. Enero-Abril 2017. Págs. 253-272.

Como es sabido, la Ley Orgánica 2/1986, de 13 de marzo, de Fuerzas y Guerpos de Seguridad, tras atribuir las funciones de Policía Judicial a las Fuerzas y Cuerpos de Seguridad del Estado, asigna a los Cuerpos de Policía Local una función de colaboración. Pues bien, este trabajo analiza la sentencia del Tribunal Supremo indicada en el título, en la cual se aborda la cuestión de la actuación de los Cuerpos de la Policía Local, en funciones colaborativas de Policía Judicial, fuera de su término municipal. A este respecto, nuestros autores admiten que el término municipal, como límite territorial para el lícito ejercicio de sus funciones por parte de los Cuerpos de la 
Policía Local, no debe poseer carácter absoluto, sino que necesariamente ha de tener cierta permeabilidad. Incluso defienden que las circunstancias de actuación supramunicipal previstas actualmente en el art. 51.3 Ley Orgánica 2/1986 (los cuerpos de Policía Local «sólo podrán actuar en el ámbito territorial del municipio respectivo, salvo en situaciones de emergencia y previo requerimiento de las autoridades competentes») son «claramente insuficientes y no dan una adecuada solución a una realidad operacional infinitamente más compleja», admitiendo así la necesidad de ampliar las causas de actuación supramunicipal recogidas en dicho precepto legal.

Ahora bien, lo anterior no impide a los autores cuestionar la escasa fundamentación del criterio reflejado en la sentencia objeto de comentario, a partir de una confusa doctrina del Tribunal Constitucional (relativa a la situaciones de «necesidad» previstas en algunas leyes autonómicas), pues podría suponer anular el reparto competencial existente, abriendo la veda a que los cuerpos de policía local de cualquier municipio - incluso sin comunicación previa - pudieran investigar a su libre albedrío en cualquier otro municipio por el mero hecho de tener cierto nexo con el de su pertenencia. Para evitar situaciones como ésta, los autores propugnan una reforma legal que actualice el modelo policial español y que, entre otros aspectos, reconozca el lugar que a los Cuerpos de la Policía Local les corresponde, dando cobertura legal a la ingente cantidad de funciones atípicas que muchos de ellos realizan cotidianamente.

(6) § Sectores Administrativos de Intervención. Derecho Administrativo económico (Aguas, Montes, Minas, Costas, Agricultura y pesca, Urbanismo y Ordenación del territorio, Medio ambiente, Energía, Telecomunicaciones, Patrimonio cultural, etc.).

López RAmón, Fernando: «El peso de la tradición sectorial en el régimen de las obras públicas», Revista Aragonesa de Administración Pública, núm. 47-48, Zaragoza, 2016, pp. 117-149.

El prof. López Ramón nos ofrece en este trabajo una síntesis de la evolución del régimen jurídico de las obras públicas en España desde los albores del régimen constitucional durante la Regencia de María Cristina hasta el presente, demostrando la importancia que han tenido y continúan teniendo los planteamientos sectoriales. Así, el autor considera que la tradición nos ofrece, desde la primera legislación del siglo XIX en la materia (la «época dorada» de las obras públicas), los elementos constitutivos del sector: los aspectos orgánicos proporcionados por el Ministerio de Fomento y el cuerpo de Ingenieros de Caminos, Canales y Puertos, el establecimiento del régimen expropiatorio liberal y sus transformaciones, y la regulación material 
contenida en la legislación de obras públicas de la Restauración, en la que se plasma un marco conceptual propio.

Para nuestro autor, esas iniciales características, pese a experimentar quiebras y embates en el período franquista (desde la época de la autarquía a la planificación del desarrollo), continúan en buena medida vigentes en el régimen actual de las obras públicas. No obstante, el prof. LÓPEZ RAMÓN constata cómo principalmente desde los años 90 determinadas prácticas y reformas legales han incidido en el régimen de las obas públicas, fundamentalmente mediante técnicas de planificación estratégica e ingeniería financiera (con objeto de estimular la financiación privada). Como bien afirma el autor, mediante estas técnicas (que no parece casual que acompañaron a una época de despilfarro y corrupción generalizados) se ha tratado sustancialmente, no tanto innovar el régimen de las obras púbicas, como eludir las garantías esenciales del sistema, de tal modo que, en vez de progreso jurídico, habría que hablar de un proceso de degradación jurídica. Pero, además, el autor aborda la penetración en el sector de las obras públicas de los nuevos intereses públicos relacionados con la ordenación del territorio, el urbanismo y la protección del medio ambiente, cuya efectiva realización ha tratado de limitarse en no pocos casos (como la extensión de la exclusión de licencia municipal para obras de interés general). En concreto, respecto al interés público ambiental, el autor sostiene que la atribución de la competencia del Estado para la evaluación de impacto ambiental de las obras estatales contenida en la legislación básica no debería traducirse en una visión subordinada del interés público de protección ambiental, el cual ha de poder expresarse libre y plenamente, dotando para ello de separación orgánica e independencia funcional al correspondiente órgano ambiental.

Soro MAteo, Blanca: La revisión de concesiones de uso privativo de agua para su adaptación a las exigencias ambientales de los planes hidrológicos y su eventual indemnización, Revista Aragonesa de Administración Pública, núm. 47-48, 2016, pp. 151-179.

En una manifestación más de la llamada ecologización del derecho de aguas, este estudio analiza la necesidad de reinterpretar y replantear la revisión de las concesiones de uso privativo del agua previamente concedidas (rescate o revocación, y revisión o modificación, según los casos), como consecuencia de sobrevenidas exigencias ambientales, esto es, por exigencias de los nuevos caudales ecológicos fijados en la planificación hidrológica o de medidas ambientales derivadas de los resultados de la evaluación ambiental de los planes o de la prevalencia de la planificación de los recursos naturales y de la protección de los espacios naturales, incluida la Red Natura 2000.

Pero, además, la autora se plantea si esta revocación y revisión de concesiones hidráulicas como consecuencia de su adaptación a las exigencias ambientales, genera 
o no un derecho a indemnización de los titulares de las concesiones preexistentes. Según la autora, aun cuando el punto de partida es el reconocimiento de indemnización derivado de la revisión de concesiones cuando lo exija su adecuación a los planes hidrológicos, es necesaria la reformulación de esta solución legal en función de la distinta naturaleza de las exigencias de los planes hidrológicos. En concreto, la autora considera que deberían considerarse de modo separado las consecuencias jurídicas derivadas de la revisión de concesiones de uso privativo del agua, cuando dicha reconsideración o modificación responda a nuevas exigencias derivadas de la discrecionalidad del planificador en materia de aguas, respecto de aquellas que pudieran derivarse del ejercicio de competencias normativas en materia de aguas o de medio ambiente, como lo es por ejemplo el establecimiento de caudales ecológicos y otros requerimientos ambientales. En este segundo caso, y de acuerdo con las reglas generales del régimen de los bienes públicos, cuando la modificación del Plan hidrológico al que debe ajustarse una concesión demanial se encontrara motivada en el interés público ambiental como prevalente sobre otros intereses tenidos en cuenta al otorgar la concesión, la autora considera que no debería proceder la indemnización, en la medida en que en este caso sí existe el deber jurídico de soportar los eventuales perjuicios derivados del ejercicio de la potestad de revisión por motivos de oportunidad.

SAncho Gargallo, Miguel Ángel: «Reflexiones sobre la autonomía de la escuela pública», Revista Aragonesa de Administración Pública, núm. 47-48, 2016, pp. 276-294.

Como señala el autor, la consideración de la educación como derecho humano fundamental y su dimensión esencial de libertad deben llevar aparejadas la posibilidad de que exista en los sistemas educativos una variedad y pluralidad de centros que respondan a la libre elección de las familias. En este contexto, el principio de autonomía escolar haría posible esa libertad de elección en función de proyectos educativos variados. Pero el autor de este estudio se cuestiona, ¿hasta qué punto cabe la autonomía y, en consecuencia, una cierta diversidad y pluralismo entre los centros públicos? Para dar respuesta a este interrogante, el autor analiza la naturaleza jurídica de la escuela pública, y examina la regulación de la autonomía escolar en el derecho español vigente.

Como indica nuestra autor, la conceptualización misma de centro educativo (que define como unidad administrativa desconcentrada de la Administración, sin personalidad jurídica independiente), su engarce dentro del Derecho de organización de la Administración, y el análisis jurídico de cómo inciden en él el marco competencial, las técnicas de desconcentración, transferencia, el control de la Administración y el principio de jerarquía al que se ve sometido, no han sido hasta la fecha objeto de un estudio suficientemente amplio y sistemático. Asimismo, en relación con la regulación vigente, el autor señala la distancia que se abre entre las 
proclamaciones de la relevancia autonomía de los centros educativos contenidas en las exposiciones de motivos de los textos legales y la verdadera capacidad que las mismas normas conceden a los centros, muy lejos de las experiencias de otros países con sistemas educativos avanzados, e los cuales se reconoce una autonomía con recursos adaptados a las necesidades de los centros.

\section{(7) § Varia.}

Ureña SAlcedo, Juan Antonio: «La (des)protección de la propiedad intelectual de las obras del poder público», Revista Vasca de Administración Pública, núm. 107-I. Enero-Abril 2017. Págs. 199-232.

Este interesantísimo artículo de tan sugerente título presenta dos partes bien diferenciadas. En la primera, el autor vincula la desprotección por las normas de propiedad intelectual de las obras vinculadas al ejercicio del poder público (ya sea el Legislativo, el Ejecutivo o el Judicial), a la transparencia pública, verdadero paradigma del Derecho Público actual. Así, el autor trata la exclusión de la propiedad intelectual de las disposiciones legales o reglamentarias y sus correspondientes proyectos, de las resoluciones de los órganos jurisdiccionales, y, en general, de los actos, acuerdos, deliberaciones y dictámenes de los organismos públicos. Asimismo, el autor plantea algunos obstáculos legales a la transparencia y, en particular, la utilización por parte de algunas leyes sobre transparencia pública de los derechos de propiedad intelectual como límite al derecho de acceso a la información pública y a su reutilización. Con todo, el autor sostiene, con fundamentos sólidos, que los derechos de propiedad intelectual de terceros no deben ser un límite al acceso, pues como señala el autor «La propiedad intelectual no protege las ideas sino su forma de expresión concreta».

En la segunda parte del estudio se aportan argumentos a favor de que la titularidad de los derechos de propiedad intelectual corresponde a la Administración para la que se trabaja, lo que debería, además, facilitar la transparencia en el ejercicio del poder público, el acceso a la información por la ciudadanía y, llegado el caso, la reutilización de la misma. Para ello el autor lleva a cabo una síntesis del estado de la cuestión, tanto legal como jurisprudencial, aportando también apuntes de Derecho comparado. Asimismo, el autor trae a colación la semejanza con la propiedad industrial de los investigadores, la presunción legal de cesión de derechos en la contratación administrativa (el contrato de servicios del sector público), y la analogía con el régimen de los trabajadores asalariados y la protección del empleador. Con todo, el autor admite que, debido a la complejidad de la organización administrativa y de las diferentes actividades que llevan a cabo las Administraciones, pueden existir supuestos dudosos. Para resolver estos casos el autor propone partir de un análisis de las funciones reservadas al puesto, para determinar si la obra se ha realizado efectivamente en cumplimiento de una función pública. 